Research article

\title{
Characterisation of atypical enteropathogenic $E$. coli strains of clinical origin
}

Sharon M Tennant ${ }^{\dagger 1,3}$, Marija Tauschek ${ }^{\dagger 1}$, Kristy Azzopardi ${ }^{1}$, Andrea Bigham ${ }^{1}$, Vicki Bennett-Wood ${ }^{1}$, Elizabeth L Hartland ${ }^{1}$, Weihong $\mathrm{Qi}^{2,4}$, Thomas S Whittam² and Roy M Robins-Browne*1

\author{
Address: ${ }^{1}$ Department of Microbiology and Immunology, The University of Melbourne, and Murdoch Childrens Research Institute, Royal \\ Children's Hospital, Victoria 3010, Australia, ${ }^{2}$ Microbial Evolution Laboratory, National Food Safety and Toxicology Center, Michigan State \\ University, Michigan, USA, ${ }^{3}$ Center for Vaccine Development, University of Maryland School of Medicine, Baltimore, MD 21201, USA and \\ ${ }^{4}$ Functional Genomics Center Zurich, Uni/ETH Zurich, Winterthurerstrasse 190/Y32 H66, CH-8057 Zurich, Switzerland \\ Email: Sharon M Tennant - stennant@medicine.umaryland.edu; Marija Tauschek - matan@unimelb.edu.au; \\ Kristy Azzopardi - kristy.azzopardi@mcri.edu.au; Andrea Bigham - bighams@foxall.com.au; Vicki Bennett-Wood - vrbwood@unimelb.edu.au; \\ Elizabeth L Hartland - hartland@unimelb.edu.au; Weihong Qi - Weihong.Qi@fgcz.ethz.ch; Thomas S Whittam - whittam@msu.edu; \\ Roy M Robins-Browne* - r.browne@unimelb.edu.au \\ * Corresponding author †Equal contributors
}

Published: 3 June 2009

BMC Microbiology 2009, 9:117 doi:10.1186/147|-2180-9-117
Received: 9 March 2009

Accepted: 3 June 2009

This article is available from: http://www.biomedcentral.com/I47I-2180/9/117

(c) 2009 Tennant et al; licensee BioMed Central Ltd.

This is an Open Access article distributed under the terms of the Creative Commons Attribution License (http://creativecommons.org/licenses/by/2.0), which permits unrestricted use, distribution, and reproduction in any medium, provided the original work is properly cited.

\begin{abstract}
Background: Enteropathogenic E. coli (EPEC) is a prominent cause of diarrhoea, and is characterised in part by its carriage of a pathogenicity island: the locus for enterocyte effacement (LEE). EPEC is divided into two subtypes according to the presence of bundle-forming pili (BFP), a fimbrial adhesin that is a virulence determinant of typical EPEC (tEPEC), but is absent from atypical EPEC (aEPEC). Because aEPEC lack BFP, their virulence has been questioned, as they may represent LEE-positive Shiga toxin-producing E. coli (STEC) that have lost the toxin-encoding prophage, or tEPEC that have lost the genes for BFP. To determine if aEPEC isolated from humans in Australia or New Zealand fall into either of these categories, we undertook phylogenetic analysis of 75 aEPEC strains, and compared them with reference strains of EPEC and STEC. We also used PCR and DNA hybridisation to determine if aEPEC carry virulence determinants that could compensate for their lack of BFP.
\end{abstract}

Results: The results showed that aEPEC are highly heterogeneous. Multilocus sequence typing revealed that $6 \mathrm{I}$ of $75 \mathrm{aEPEC}$ strains did not belong to known tEPEC or STEC clades, and of those that did, none expressed an O:H serotype that is frequent in tEPEC or STEC strains associated with disease. PCR for each of 18 known virulence-associated determinants of $E$. coli was positive in less than $15 \%$ of strains, apart from $\mathrm{NleB}$ which was detected in $30 \%$. Type I fimbriae were expressed by all aEPEC strains, and 12 strains hybridised with DNA probes prepared from either $b f p A$ or $b f p B$ despite being negative in the PCR for $b f p A$.

Conclusion: Our findings indicate that clinical isolates of aEPEC obtained from patients in Australia or New Zealand are not derived from tEPEC or STEC, and suggest that functional equivalents of BFP and possibly type I fimbriae may contribute to the virulence of some aEPEC strains. 


\section{Background}

Strains of enteropathogenic E. coli (EPEC) are a well-recognised cause of diarrhoea, particularly in children in less developed countries $[1,2]$. EPEC are characterised in part by their ability to induce attaching-effacing (A/E) lesions in the intestine [3-5]. These lesions are comprised of bacteria intimately attached to the intestinal mucosa at sites of cytoskeletal rearrangements leading to characteristic morphological changes, known as cupping and pedestal formation, accompanied by the absence of microvilli. The genes required for the production of these lesions are located on a pathogenicity island known as the locus for enterocyte effacement (LEE), which encodes (i) intimin, an outer membrane protein product of the eae gene that acts as an adhesin, (ii) a type III protein secretory system, and (iii) several effector proteins secreted by the type III system, including a translocated intimin receptor, Tir, which, once bound to intimin, serves as an anchor for host cytoskeletal proteins [6]. EPEC is divided into two subtypes: typical and atypical. Typical EPEC (tEPEC) strains carry a ca. 90-kb EPEC adherence factor plasmid (pEAF) that encodes type IV-like bundle-forming pili (BFP) [7]. The latter facilitate the adherence of bacteria to the intestinal mucosa and to each other, allowing them to form micro-colonies on epithelial cells in vitro and in vivo $[8,9]$. Studies with adult volunteers have demonstrated that intimin, pEAF and BFP are essential virulence determinants of EPEC [10-12]. Interestingly, there is evidence that a subset of EPEC strains, known as atypical EPEC (aEPEC), which lack pEAF and BFP, are also pathogenic [2].

aEPEC is defined as E. coli which possess LEE, but lack pEAF/BFP and do not produce Shiga toxins [13]. Evidence of the pathogenicity of aEPEC comes from case control studies of paediatric diarrhoea in several countries throughout the world, including Australia, Iran, Norway, Peru, Poland, South Africa, the United Kingdom and the USA (reviewed in $[2,14]$ ). In addition, at least three separate studies have shown an association between infection with aEPEC and persistent diarrhoea in children [14-16]. Notwithstanding these reports, the pathogenicity of aEPEC remains controversial, chiefly because several studies have found aEPEC in patients with diarrhoea and control subjects at similar frequencies. These conflicting observations prompt the question of whether aEPEC comprise a homogeneous group of pathogens with shared virulence determinants, such as adhesins analogous to BFP, or whether they are heterogeneous, with one or more subsets being more virulent than others. Although some clinical isolates of $\mathrm{A} / \mathrm{E}$ strains of $E$. coli which meet the definition of aEPEC, appear to be Shiga-toxin producing strains of E. coli (STEC) that have lost the Shiga toxinencoding bacteriophage(s) during passage through the intestine [17], others may be tEPEC strains that have lost
pEAF [12]. Alternatively, aEPEC may represent a distinct subset of human-specific strains of A/E E. coli or be acquired from domestic animals, such as calves and rabbits, that are commonly infected with EPEC strains, which lack pEAF $[18,19]$. In this study we characterised a large number of clinical isolates of aEPEC from humans by multi-locus sequence typing (MLST), PCR and/or DNA hybridisation for $E$. coli virulence-associated determinants, intimin type, HEp-2 adherence pattern and type 1 pilus production as a way of addressing these questions.

\section{Results \\ MLST analysis}

We have previously reported that aEPEC isolates obtained during a water quality study were heterogeneous in terms of serotype, intimin type and patterns of adherence to HEp-2 cells [20]. This overall heterogeneity was confirmed by MLST analysis, which showed that 56 of the 79 aEPEC strains of human origin investigated in the study belonged to one of 11 different clades and that 23 strains could not allocated to a clade (Figure 1 ). As observed with phylogenetic analyses of A/E strains of E. coli in general, there was a tendency for each clade to contain strains with the same intimin and flagellar type. Five of 11 clades which contained aEPEC strains in this study were clades that include either tEPEC or STEC strains, whereas six clades were apparently distinct for aEPEC. These six clades comprised one which contained three strains with intimin- $\beta$ and $\mathrm{H} 7$ (and O-antigens, O25 or O153); one clade with seven strains with intimin- $v$ and H19 (all Onontypable [nt]); one clade with six strains with intimin$\theta$ and $\mathrm{H} 21$ (O119 and Ont); a clade with five strains with intimin-1 and $\mathrm{H} 8$ or $\mathrm{H}-(\mathrm{O} 98, \mathrm{O} 107$ or O177); one with four strains with intimin- $\mathrm{\kappa}$ and $\mathrm{H} 10$ or $\mathrm{H}-(\mathrm{O} 49$, O88, and O153), and one with 13 strains with intimin- $\alpha$ and $\mathrm{H} 6$ or H34 (O71, O125, O126, and Ont). The last-mentioned clade was closely related to a tEPEC clade (EPEC-1), which also comprises strains with intimin- $\alpha$ and flagellar antigen, H6.

Of the strains that clustered with known clades of tEPEC or EHEC, three (all intimin- $\gamma$ and O55:H7) belonged to the EHEC-1 clade, which also includes the pandemic, prototypical O157:H7 EHEC clone. Five aEPEC isolates grouped within the EPEC-2 clade which includes pEAF/ BFP-positive strains with intimin- $\beta$ and H2. The aEPEC serotypes in this clade included O15:Hnt, O114:H2, O117:H2, O128:H2, and Ont:H2. This clade also contained the prototypical aEPEC strain, E128012 [12], two rabbit-specific EPEC (REPEC) strains, 84/110/1 and E22 (both of which carry intimin- $\beta$ and are serotype O103:H2), and a calf isolate, also O103:H2, but with intimin- $\varepsilon$. Four aEPEC strains were assigned to the EPEC4 clade (intimin- $\beta$ and H6). All of these strains were intimin- $\beta$; two were O33:H6, and the others were 


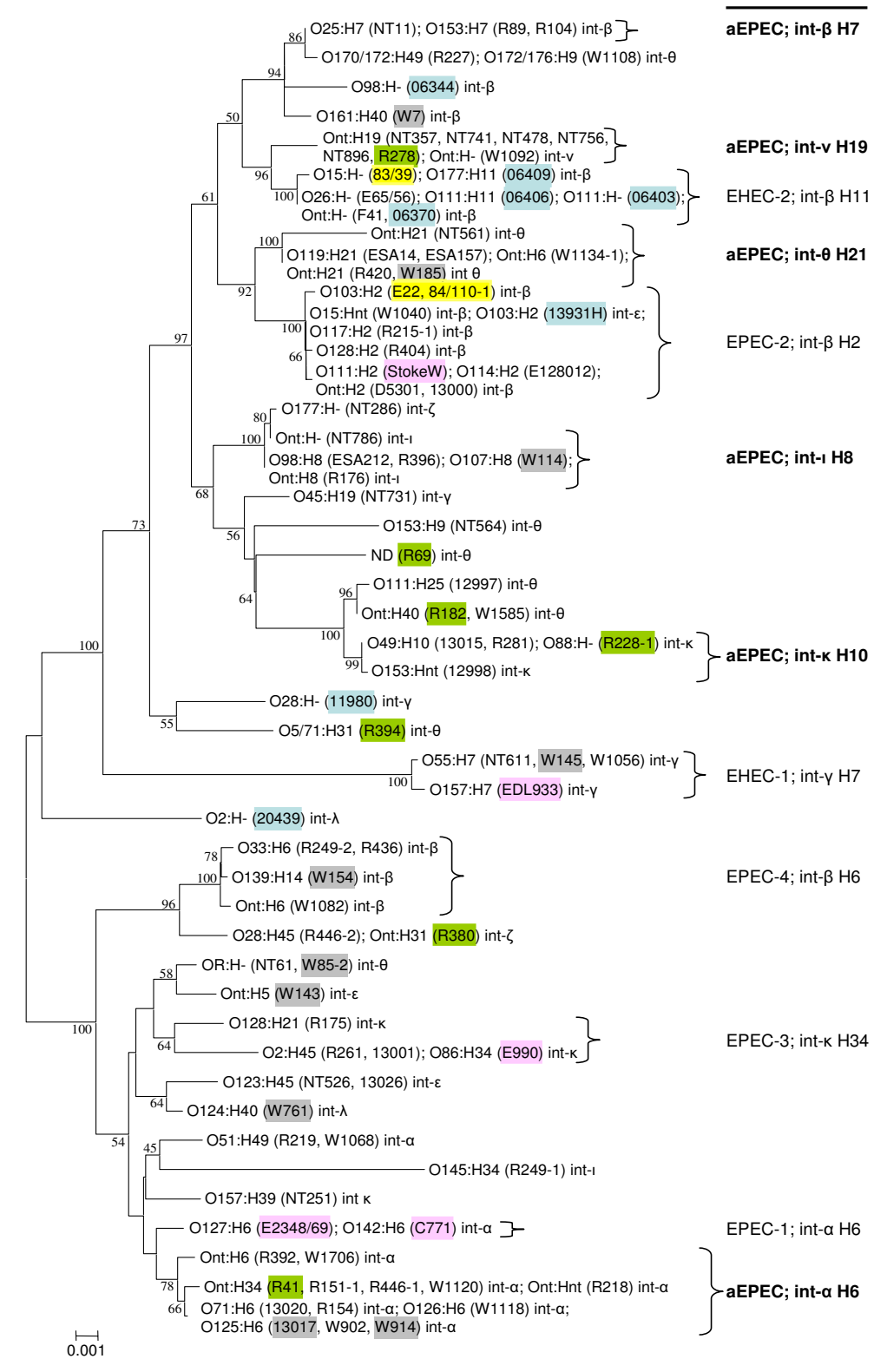

Figure I

Phylogenetic relationships of sequence types of 95 strains of attaching-effacing $E$. coli. An unrooted phylogenetic tree was constructed by the neighbour-joining algorithm based on the Kimura two-parameter model of nucleotide substitution. Bootstrap values greater than $50 \%$ based on 500 replications are given at the internal nodes. Strain names highlighted in pink are reference strains of typical EPEC or STEC; those highlighted in pale blue and yellow were originally isolated from cattle and rabbits, respectively, those highlighted in green were from children with persistent diarrhoea, and those highlighted in grey were from humans without diarrhoea. The right hand column indicates distinctive aEPEC clades in boldface type. The intimin and flagella type is shown for each clade. Abbreviations: nt, non-typable; int, intimin; ND, not determined. 
O139:H14 and Ont:H6. Two aEPEC strains, both O2:H4, intimin- $\kappa$, belonged to the EPEC-3 clade, which also included tEPEC strain O86:H34, intimin- $\kappa$. Overall, three of 75 Australian and New Zealand isolates from humans reported here belonged to EHEC clades, 11 fell within EPEC clades, 38 belonged to clades distinct for aEPEC, and 23 could not be classified.

Of the eight Australian calf isolates examined, three were not assigned to a particular clade, and four belonged to the EHEC- 2 clade (intimin- $\beta$ and H11), but were of different serotypes from each other (O111:H-, O111:H11, O177:H11 and Ont:H-). This clade also included archetypal aEPEC strains E65/56 (O26:H-) and F41 (Ont:H-), which were isolated in Europe more than 50 years ago, and a well-studied, REPEC strain, 83/39 (O15:H-), in which Ral, a K88-like adhesin, was first identified [21]. None of the Australian or New Zealand strains of human origin investigated in this study belonged to this clade, suggesting that there was no major exchange of aEPEC strains between the cattle and humans from whom these bacteria were obtained. One calf isolate (O103:H2) was assigned to the EPEC-2 clade, which also contained REPEC strains E22 and 84/110-1 (also O103:H2), tEPEC strain, Stoke W (O111:H2), and the prototypical aEPEC strain, E128012 (O114:H2). No aEPEC strains carrying intimin- $\beta 2,-\xi,-0,-\rho$ or $-\sigma$ were identified in the entire collection of 87 test and 8 reference strains reported here.

\section{Frequency of adhesins and other virulence determinants of pathogenic E. coli in aEPEC strains}

None of the 67 Australian aEPEC strains of human origin investigated in this study was positive in the PCR for genes encoding the following adhesins of pathogenic E. coli: BFP, Lda, Pap, Saa, Afa, Sfa/Foc, K88, K99, Af/R2 or RalG (Table 1). On the other hand, all strains were positive in the PCR for FimH of Type 1 pili. Moreover, all isolates exhibited mannose-sensitive haemagglutination, indicating that they produced functional Type 1 pili.

One strain, NT731 (O45:H19, intimin- $\gamma$ ) was the only one of the 67 aEPEC isolates investigated that was positive in the PCR for Afa, a virulence determinant of uropathogenic E. coli that also serves as an adhesin in some EPEC strains $[22,23]$.

Two strains, R89 and R104, which belonged to a distinct aEPEC clade, characterised by intimin- $\beta$ and $H 7$ flagella, were positive in the PCR for AF/R1, a fimbrial adhesin and essential virulence determinant of the prototypical REPEC strain, RDEC-1 [24]. One strain, R219 (O51:H49, intimin- $\alpha$ ), was the only one that tested positive for AggA, the pilin subunit of enteroaggregative E. coli [25]. Three strains, NT286, NT731, and NT786, were positive in the
PCR for Iha, an adherence-conferring protein that is highly prevalent in STEC [26]. The Iha-positive aEPEC strains identified here were unrelated to each other and to STEC in terms of MLST type, intimin type and serotype (Table 1, Figure 1).

The PCR for long polar fimbriae (Lpf) was positive in 13 (19\%) of 67 strains, all of which were from patients with diarrhoea. Lpf-positive strains occurred within the EPEC2 clade ( 3 strains), the aEPEC clade with intimin $-v$ and H19 ( 7 strains), and the aEPEC clade with intimin- $\beta$ and H7 ( 3 strains). Overall, seven of the LPF-positive isolates carried intimin $-v$, and six had intimin- $\beta$.

We and others have previously reported that certain determinants of EPEC, which are not encoded by LEE or the EAF plasmid, such as Efa1, NleB and the cytolethal distending toxin (Cdt) are associated with virulence in attaching-effacing E. coli $[15,27]$. NleB was detected in 20 $(30 \%)$ of the 67 strains tested, whereas Efa1 was detected in 8 strains $(12 \%)$, all of which were also positive for NleB. NleB-positive strains were distributed amongst the following clades: EHEC-1 (3 strains), EPEC-2 (2 strains), aEPEC-1 (intimin- $\beta, H 7 ; 3$ strains), aEPEC-3 (intimin- $\theta$, H21 [or H6]; 6 strains). Six NleB-positive isolates could not be assigned to a clade, although all carried intimin- $\theta$ (Table 1). The Efa1-positive strains occurred within the EHEC-1 and EPEC-2 clades, as well as within the aEPEC1 clade that was characterised by strains with intimin- $\beta$ and H7. Seven (10\%) strains were positive in the PCR for Cdt. Three of these strains belonged to the aEPEC- 6 clade (intimin- $\alpha$ and H34), one belonged to EPEC-2 (intimin$\beta, \mathrm{H} 2$ ), and three were unassigned (Table 1 ).

\section{DNA hybridization}

To determine if aEPEC carry DNA sequences related to those that code for the production of BFP, but were not amplified by the PCR for BfpA, we investigated the aEPEC strains by DNA hybridisation using probes derived from the $b f p A$ and $b f p B$ genes of EPEC strain E2348/69. Unexpectedly, six isolates (ESA212, R176, R182, R228-1, R281, and W114) hybridised with the BfpA probe at high stringency. Three of these strains belonged to the aEPEC clade with intimin- 1 and $\mathrm{H} 8$, but they belonged to different $\mathrm{O}$ serogroups. The other three probe-positive strains also differed from each other. Six strains hybridised with the BfpB probe. Four of these were positive for intimin- $\alpha$, three carried $\mathrm{H} 34$, two carried H6, but all were of different serotypes. No strain hybridised with both Bfp probes.

Some aEPEC strains from humans and animals express adhesins that are homologous to the K88 fimbriae of enterotoxigenic E. coli $[21,28]$. To determine if the aEPEC strains in our collection carried similar sequences, we 
Table I: Characteristics of atypical EPEC strains that were positive in one or more PCR or DNA hybridization assays for virulenceassociated determinants of $E$. colia

\begin{tabular}{|c|c|c|c|c|c|c|c|c|c|c|c|c|c|c|}
\hline \multirow[b]{3}{*}{ Strain } & \multirow[b]{3}{*}{ Serotype } & \multirow[b]{3}{*}{ Clade } & \multirow[b]{3}{*}{ Intimin } & \multicolumn{10}{|c|}{ Result of assay using: } & \multirow[b]{3}{*}{ HEp-2 adhesion } \\
\hline & & & & \multicolumn{8}{|c|}{ PCR for } & \multicolumn{2}{|c|}{ Probe for } & \\
\hline & & & & Afa & Afr/l & AggA & $\mathrm{Cdt}$ & Efal & Iha & LpfD & NleB & BfpA & $\mathrm{Bfp} B$ & \\
\hline ESAI 4 & $\mathrm{O} 119: \mathrm{H} 21$ & aEPEC3 & $\theta$ & - & - & - & - & - & - & - & + & - & - & NA \\
\hline ESAI57 & $\mathrm{O} 119: \mathrm{H} 21$ & aEPEC3 & $\theta$ & - & - & - & - & - & - & - & + & - & - & NA \\
\hline ESA2 12 & O98:H8 & aEPEC4 & 1 & - & - & - & - & - & - & - & - & + & - & NA \\
\hline NTII & O25:H7 & aEPECI & $\beta$ & - & - & - & - & + & - & + & + & - & - & $\mathrm{IA}$ \\
\hline NT286 & Ol77:H- & & $\zeta$ & - & - & - & - & - & + & - & - & - & - & NA \\
\hline NT357 & Ont:HI9 & aEPEC2 & v & - & - & - & - & - & - & + & - & - & - & IA \\
\hline NT478 & Ont:HI9 & aEPEC2 & $v$ & - & - & - & - & - & - & + & - & - & - & NA \\
\hline NT526 & OI23:H45 & & $\varepsilon$ & - & - & - & + & - & - & - & - & - & - & IA \\
\hline NT56I & Ont:H2I & aEPEC3 & $\theta$ & - & - & - & - & - & - & - & + & - & - & AA \\
\hline NT6II & O55:H7 & EHECI & $\gamma$ & - & - & - & - & + & - & - & + & - & - & AA \\
\hline NT73I & O45:HI9 & & $\gamma$ & + & - & - & - & - & + & - & - & - & - & NA \\
\hline NT74I & Ont:HI9 & aEPEC2 & $v$ & - & - & - & - & - & - & + & - & - & - & IA \\
\hline NT756 & Ont:HI9 & aEPEC2 & $v$ & - & - & - & - & - & - & + & - & - & - & IA \\
\hline NT786 & OR:H- & aEPEC4 & 1 & - & - & - & - & - & + & - & - & - & - & AA \\
\hline NT896 & Ont:HI9 & aEPEC2 & $v$ & - & - & - & - & - & - & + & - & - & - & IA \\
\hline RI04 & O153:H7 & aEPECI & $\beta$ & - & + & - & - & + & - & + & + & - & - & AA \\
\hline RI5I-I & Ont:H34 & aEPEC6 & $\alpha$ & - & - & - & + & - & - & - & - & - & + & AA \\
\hline RI76 & Ont:H8 & aEPEC4 & 1 & - & - & - & - & - & - & - & - & + & - & NA \\
\hline RI82 & OR:H40 & & $\theta$ & - & - & - & - & - & - & - & + & + & - & IA \\
\hline R2I5-I & Ol17:H2 & EPEC2 & $\beta$ & - & - & - & - & + & - & + & + & - & - & IA \\
\hline R218 & Ont:R & aEPEC6 & $\alpha$ & - & - & - & + & - & - & - & - & - & + & AA \\
\hline R219 & O51:H49 & & $\alpha$ & - & - & + & - & - & - & - & - & - & - & AA \\
\hline R227 & OI70/I72:H49 & & $\theta$ & - & - & - & - & - & - & - & + & - & - & IA \\
\hline R228-I & O88:H- & aEPEC5 & $\kappa$ & - & - & - & - & - & - & - & - & + & - & NA \\
\hline R249-I & OI45:H34 & & 1 & - & - & - & - & - & - & - & - & - & + & AA \\
\hline R278 & Ont:HI9 & aEPEC2 & $v$ & - & - & - & - & - & - & + & - & - & - & IA \\
\hline R28I & O49:HIO & aEPEC5 & $\kappa$ & - & - & - & - & - & - & - & - & + & - & NA \\
\hline R380 & Ont:H3I & & $\zeta$ & - & - & - & + & - & - & - & - & - & - & AA \\
\hline R392 & Ont:H6 & aEPEC6 & $\alpha$ & - & - & - & - & - & - & - & - & - & + & $A A$ \\
\hline R394 & O5/7I:H3| & & $\theta$ & - & - & - & - & - & - & - & + & - & - & IA \\
\hline R404 & O128:H2 & EPEC2 & $\beta$ & - & - & - & + & - & - & + & - & - & + & LA-L \\
\hline R420 & Ont:H2I & aEPEC3 & $\theta$ & - & - & - & - & - & - & - & + & - & - & IA \\
\hline R446-I & Ont:H34 & aEPEC6 & $\alpha$ & - & - & - & + & - & - & - & - & - & + & AA \\
\hline R446-2 & O28:H45 & & $\zeta$ & - & - & - & + & - & - & - & - & - & - & $A A$ \\
\hline R69 & NT & & $\theta$ & - & - & - & - & - & - & - & + & - & - & IA \\
\hline R89 & OI53:H7 & aEPECI & $\beta$ & - & + & - & - & + & - & + & + & - & - & IA \\
\hline W1040 & OI5:Hnt & EPEC2 & $\beta$ & - & - & - & - & + & - & + & + & - & - & LA-L \\
\hline W1056 & O55:H7 & EHECI & $\gamma$ & - & - & - & - & + & - & - & + & - & - & IA \\
\hline W1092 & OR:H- & aEPEC2 & $v$ & - & - & - & - & - & - & + & - & - & - & IA \\
\hline W1108 & OI76/I72:H49 & & $\theta$ & - & - & - & - & - & - & - & + & - & - & IA \\
\hline WII34-I & Ont:H6 & aEPEC3 & $\theta$ & - & - & - & - & - & - & - & + & - & - & NA \\
\hline WII4 & O107:H8 & aEPEC4 & 1 & - & - & - & - & - & - & - & - & + & - & NA \\
\hline WI45 & O55:H7 & EHECI & $\gamma$ & - & - & - & - & + & - & - & + & - & - & AA \\
\hline WI585 & Ont:H40 & & $\theta$ & - & - & - & - & - & - & - & + & - & - & NA \\
\hline W185 & Ont:H2I & aEPEC3 & $\theta$ & - & - & - & - & - & - & - & - & - & - & IA \\
\hline
\end{tabular}

a No strain was positive in the PCR for BFP, Lda, Pap, Saa, Afa, Sfa/Foc, K88, K99, Af/R2 or RalG, and no strain hybridised with a probe for K88. All strains were positive in the PCR for FimH. ${ }^{b}$ Adherence pattern after 3 hours' incubation with HEp-2 cells: AA, aggregative adherence; IA, indeterminate pattern; LA-L, localised-like adherence; NA, non-adherent. 
probed these strains for the fae gene of K88, but none of the aEPEC hybridised with this probe, even when tested at low stringency.

\section{Adherence to HEp-2 cells}

After incubation for three hours with HEp-2 cells, 54 (81\%) of 67 aEPEC strains were adherent: 24 strains adhered in an aggregative pattern, and two in the pattern termed "localised-like adherence", because it resembles BFP-mediated localised adherence, but the bacteria are more loosely associated with each other than BFP-bearing strains. Twenty-eight strains showed an indeterminate pattern of adherence described previously [20], in which bacteria adhere in a mixed pattern of diffuse and localised-like adherence. Thirteen strains did not adhere to HEp-2 cells after 3 hours. Extending the contact period of the bacteria with the HEp-2 cells from 3 to 6 hours allowed some strains that had not adhered after 3 hours to adhere in an indeterminate pattern, but the pattern of strains that were adherent after 3 hours did not change.

Five of the six strains that hybridised with the BfpA probe were non-adherent after three hours, whereas five of the six BfpB-positive strains showed aggregative adherence and one showed localised-like adherence. Adherence to HEp-2 cells was not associated with a positive PCR for either Lpf or Efa.

\section{Association of specific virulence determinants with clinical presentation}

The 67 aEPEC strains we investigated by PCR, DNA hybridisation and for adherence to HEp-2 cells originated from individuals with different clinical presentations (Table 2). Fifty-seven isolates were obtained from patients with diarrhoea, and ten were from asymptomatic individuals. Eleven isolates were from children with persistent diarrhoea (i.e., diarrhoea lasting more than 14 days), and 12 were from children with diarrhoea less than 14 days in duration. Thirty-four strains were from patients in whom the duration of diarrhoea was not known. To determine if any of the putative accessory virulence determinants of aEPEC that were sought in this study were associated with a particular clinical presentation, we compared the fre- quency of these determinants in isolates from patients with and without diarrhoea, and those known to have acute or persistent diarrhoea. The results showed that the frequency of the factors investigated did not differ significantly between the groups under comparison $(\mathrm{P}>0.1$, Fisher's exact test, two-tailed).

\section{Discussion}

The classification of diarrhoeagenic strains of $E$. coli into pathotypes has led to considerable improvement in our understanding of the epidemiology, pathogenesis and clinical presentation of infections with these bacteria, and has spawned novel strategies to diagnose and prevent these infections $[29,30]$. Each pathotype of diarrhoeagenic E. coli carries a distinctive suite of virulence determinants, almost all of which show evidence of having been acquired on mobile genetic elements, such as plasmids, transposons, bacteriophages and pathogenicity islands. Interestingly, apart from their shared virulence determinants, strains of each pathotype often differ from each other in terms of serotype, biotype, phage type, and even with regard to the nature of the specific virulence determinants they carry, e.g., Shiga toxin-1 or Shiga toxin-2 in EHEC, and heat-labile or heat-stable enterotoxin in enterotoxigenic E. coli [30,31].

It was not surprising, therefore, that the clinical isolates of aEPEC we examined in this study were heterogeneous in every way we investigated them, including by using MLST to examine their phylogenetic relatedness. This analysis confirmed that some strains are closely related to tEPEC, while others are more like EHEC [32]. Indeed, one of the aims of this study was to determine if aEPEC obtained from patients with diarrhoea are derived from tEPEC that have lost pEAF [12], or LEE-positive STEC strains that have been cured of the Stx-encoding bacteriophage [17]. Phylogenetic analysis revealed that 3 aEPEC strains obtained from 75 humans in Australia or New Zealand belonged to EHEC clades, and 11 belonged to clades that contain tEPEC. None of these 14 isolates belonged to serotypes of highly virulent or epidemic EHEC or EPEC and none carried the gene for EHEC-haemolysin $[14,20,33]$, suggesting that they did not recently arise

Table 2: Frequency of putative virulence-associated determinants of atypical EPEC strains in study subjects with different clinical presentations.

\begin{tabular}{|c|c|c|c|c|c|c|}
\hline \multirow[b]{2}{*}{ Clinical presentation } & \multicolumn{6}{|c|}{ No. of strains positive for:a } \\
\hline & BfpA & BfpB & $C d t$ & Efal & Lpf $_{\mathrm{O} / 13}$ & $\mathrm{NleBI}$ \\
\hline All diarrhoea $(n=57)$ & 5 & 6 & 7 & 7 & 13 & 18 \\
\hline No diarrhoea $(n=10)$ & I & 0 & 0 & I & 0 & 2 \\
\hline Acute diarrhoea $(n=12)$ & 1 & 4 & 4 & 2 & 3 & 3 \\
\hline Persistent diarrhoea $(\mathrm{n}=\mathrm{II})$ & 2 & 0 & I & 0 & 1 & 4 \\
\hline
\end{tabular}

a Only determinants that were present in more than three isolates overall were included in this analysis. 
from EHEC strains. On the other hand, it was not surprising that three aEPEC strains, which were clustered together with EHEC O157:H7, were serotype O55:H7, given the evidence that the latter appears to be the progenitor of EHEC O157:H7 [34].

Most of the strains we investigated (61 of 75) either belonged to distinctive aEPEC clades or could not be classified, indicating further that they did not arise from EHEC or tEPEC. Even those strains which clustered with EPEC or EHEC generally were of serotypes that are not common amongst tEPEC or STEC strains that are associated with infection of humans. Our finding that each bacterial isolate within each distinctive aEPEC clade generally carried the same intimin type mirrors observations made with tEPEC [35] and provides further evidence that E. coli acquired the LEE pathogenicity island on a number of separate occasions.

aEPEC in different clades did not differ from one another in terms of their association with acute or persistent diarrhoea. This conclusion is in keeping with our somewhat unexpected finding that REPEC strains E22 and 83/39, which carry closely related virulence determinants, and are proven pathogens of infant rabbits in which they cause a similar illness, clustered with EPEC and EHEC, respectively.

Our search for virulence determinants in clinical isolates of aEPEC revealed that a minority of strains carried homologues of DNA sequences that encode known adhesins or other virulence-associated determinants of pathogenic $E$. coli. Overall, six strains each hybridised with DNA probes for BfpA and BfpB, respectively, and PCR analysis gave positive results for Lpf (13 strains), Iha (3 strains), AF/R1 (2 strains), Afa (1 strain), or AggA (1 strain). To our knowledge, this is the first time that $\mathrm{AF} / \mathrm{R} 1$ has been identified in any E. coli other than the prototypical REPEC strain, RDEC-1 [36], but we have not determined if this gene or any of the other putative virulence genes in the probe- or PCR-positive aEPEC strains we investigated is expressed by the strain that carries it. Moreover, no strain was positive in the PCR for $l d a H$, which is the only known specific adhesin of aEPEC identified so far [28].

In this study we were unable to confirm previous reports that $n l e B$ or $e f a 1$, which are key components of a genomic island of EPEC and virulent STEC [37], are markers of symptomatic infection with aEPEC [38], largely because these determinants were present in so few strains (present in only 20 and 8 of 67 strains, respectively). We also did not find any association between the presence of any genes for particular virulence determinants and the clinical presentation of patients in terms of the presence or duration of diarrhoea, but the small number of probe- or PCR-positive strains made the finding of statistically significant associations unlikely.

All of the aEPEC strains we investigated in this study expressed functional Type I pili. Although these pili are widespread amongst all varieties of $E$. coli, including nonpathogens, evidence is accumulating that these pili, which are well established virulence determinants of uropathogenic and systemically invasive E. coli $[39,40]$, may also contribute to the virulence of EPEC and enteroaggregative E. coli, particularly with respect to biofilm formation $[41,42]$. Type I pili are also an essential virulence determinant of adherent-invasive E. coli [43]. In addition, overexpression of Type I pili by a BFP-mutant of tEPEC was able to compensate for the absence of BFP and allowed bacteria to adhere to cultured epithelial cells in vitro [44]. Whether Type I pili contribute to the virulence of aEPEC, however, remains to be determined.

\section{Conclusion}

Our findings show that aEPEC are highly heterogeneous in terms of serotype, intimin type, multilocus sequence type, pattern of adherence to HEp-2 cells, and their carriage of known virulence genes (apart from those encoded by the LEE). Although we did not identify a common type of adhesive fimbria in aEPEC that is functionally equivalent to BFP, we cannot rule out that one exists. Indeed, the fact that all tEPEC strains express BFP despite their phylogenetic heterogeneity supports the case for continued efforts to identify specific adhesins of aEPEC.

\section{Methods \\ Bacteria}

For the purposes of this study, aEPEC were defined as strains of E. coli that were positive by PCR for the eae gene, but negative by PCR for the genes for BfpA and Shiga toxins 1 and 2, using the PCR primers and conditions described previously [14]. Sixty-seven of the aEPEC strains investigated in this study were isolated in our laboratory during the course of four separate studies: a Melbourne water-quality study (21 strains with a prefix of W [20], a study examining the clinical features of children infected with aEPEC at the Royal Children's Hospital, Melbourne, Australia (28 strains with a prefix of R [14]), a study of the prevalence of STEC in Melbourne (3 strains, prefixed ESA), and a study of acute diarrhoea in children in the Northern Territory, Australia (15 strains, prefixed NT [33]). The remaining clinical aEPEC isolates were E128012, from a case of sporadic infant diarrhoea in Bangladesh [12], F41 (Denmark [45]), E65/56 and D5301 (England [46-48]), all of which are archetypal aEPEC strains [49]. We also tested 8 clinical aEPEC strains from New Zealand (kindly supplied by Jenny Bennett, 
ESR Ltd., Porirua, New Zealand) and eight aEPEC strains isolated from symptomatic cattle in Australia [18] (kindly supplied by Dr Steven Djordjevic, Elizabeth Macarthur Agricultural Institute, Camden, NSW, Australia).

Reference strains of $E$. coli included in the phylogenetic analysis of the aEPEC strains were: tEPEC (eae+ bfpA+) strains, E2348/69, E990, Stoke W and C771 [12,49]; REPEC strains, E22 [50], 83/39, 84/110-1 [51], and an STEC O157:H7 strain, EDL933, which is LEE-positive and classified as enterohemorrhagic E. coli (EHEC) [52]. E. coli strains used as controls for PCR included enteroaggregative E. coli strain 17-2 [53]; STEC strains, EH41 [54], and EH52 (this study); enterotoxigenic E. coli strain K88 and E. coli K12-K99+ (courtesy of Professor Peter Reeves, University of Sydney, Sydney, NSW, Australia); REPEC strains, B10 [55], 83/39 and RDEC-1 [56], and uropathogenic E. coli strain $J 96$ [57]. Adherent-invasive E. coli strain LF82, which was isolated from a chronic ileal lesion of a patient with Crohn's disease, and 52D11 (an isogenic fimA mutant of LF82) [43] were kindly supplied by Dr Arlette Darfeuille-Michaud, Université d'Auvergne, ClermontFerrand, France, and used as controls to test for mannosesensitive haemagglutination. Unless otherwise specified, bacteria were routinely subcultured on horse blood agar or Luria-Bertani agar (BD Difco, Franklin Lakes, NJ) at $37^{\circ} \mathrm{C}$.

\section{Preparation of DNA}

Genomic DNA was isolated from E. coli using hexadecyltrimethylammonium bromide (CTAB) as described in Ausubel et al. [58], and was used as the template for all experiments requiring DNA.

\section{Multi-locus sequence typing (MLST)}

Eighty-three test strains isolated from humans or cattle in Australia and New Zealand, together with four archetypal aEPEC and eight A/E E. coli control strains were subjected to MLST analysis using the methods described on the EcMLST website http://www.shigatox.net/mlst. Briefly, seven housekeeping genes (aspC, clpX, fadD, icdA, lysP, $m d h$ and uidA) were amplified with AmpliTaq Gold in 50 $\mu \mathrm{l}$ reaction volumes. PCR products $(5 \mu \mathrm{l})$ were electrophoresed on $1 \%$ agarose gels to check the size and yield. The remaining $45 \mu \mathrm{l}$ was purified using the QIAquick PCR Purification Kit (Qiagen, Valencia, CA) and eluted in $20 \mu \mathrm{l}$ elution buffer. Both strands of each gene were sequenced using ABI PRISM BigDye Terminator (Applied Biosystems, Foster City, CA) according to the manufacturer's instructions. Sequences were checked and cropped to the required length using Sequencher 4.0 (Gene Codes, Ann Arbor, MI). Sequences were concatenated for phylogenetic analyses, and aligned with the ClustalW algorithm using the MegAlign module of the Lasergene software (DNASTAR Inc., Madison, WI). Neighbour-joining trees were constructed using the Kimura two-parameter model of nucleotide substitution with the MEGA3 software (Center for Evolutionary Functional Genomics, Tempe, AZ) [59]. The inferred phylogenies were each tested with 500 bootstrap replications.

\section{Accession numbers}

The sequences of the aspC, clpX, fadD, icdA, lys $P, m d h$ and uidA genes used for the MLST analysis have been deposited in the GenBank data base under accession numbers GQ130379 to GQ131022.

\section{Intimin typing}

The eae gene was subtyped by using the restriction fragment length polymorphism assay described by Ramachandran et al. [60]. This method permits detection of the following intimin types: $\alpha$ (alpha), $\beta$ (beta), $\beta 2, \gamma$ (gamma), $\varepsilon$ (epsilon), $\zeta$ (zeta), $\theta$ (theta), 1 (iota), $\kappa$ (kappa), $\lambda$ (lambda), $v$ (nu), $\xi$ (xi), o (omicron), $\rho$ (rho), and $\sigma$ (sigma).

\section{Detection of genes for adhesins and other virulence factors by using PCR}

PCR amplifications were performed in a GeneAmp PCR System 9700 thermal cycler (Applied Biosystems) or an iCycler (Bio-Rad Laboratories, Hercules, CA) with AmpliTaq Gold polymerase (Applied Biosystems) in a reaction volume of $20 \mu \mathrm{l}$. The genes, primers, amplicon size and PCR conditions used for these studies are listed in the additional file (see Additional file 1). The test strains for these analyses, and those described below, were the 67 aEPEC strains obtained from humans in Australia. The following E. coli strains were used as positive controls: E2348/69 (bfpA), 83/39 (efa1, ralG), EDL933 (iha, nleB1), EH41 (saa, lpfD $\left.\mathrm{O}_{\mathrm{O} 13}\right)$; K88 (fae operon), K12-K99+ (fan operon), 17-2 (aggA); J96 (fimH, papA, sfa/focDE, focG), EH52 (afaC), RDEC-1 (afr1), B10 (afr2), and E990 (cdt). PCR products were electrophoresed on $1-1.5 \%$ Tris-acetate-EDTA agarose gels and stained with ethidium bromide before visualisation on a UV transilluminator.

\section{DNA Hybridisation}

Genomic DNA was spotted onto Magna Nylon Transfer Membranes (GE Osmonics, Trevose, PA) and denatured and neutralised according to the "DIG System User's Guide for Filter Hybridisation" (Roche, Mannheim, Germany). Transferred DNA was UV-crosslinked using a Spectrolinker XL-1000 UV crosslinker (Spectronics Corp., Westbury, NY). Digoxigenin-labelled DNA probes were prepared by PCR (Roche) using primers to detect $b f p A$ (Table 1); primers MP-bfpB-F (GATAAAACTGATACTGGGCAGC) and MP-bfpB-R (AGTGACTGTTCGGGAAG$\mathrm{CAC)}$ to detect $b f p B$ [61]; and primers faeEF (ATGCGCCGGGTGATATCA) and faeER (TTATTTCTGCTCTGCGGT) to detect faeE. EPEC E2348/69 was used 
as template for the $b f p A$ and $b f p B$ probes and enterotoxigenic E. coli strain K88 was used as template for the faeE probe. These strains were also included as positive controls on the appropriate membranes. Before use, probes were sequenced using ABI PRISM Big Dye Terminator as described above. Sequencing reactions were purified using $\mathrm{MgSO}_{4}$ and submitted to the Australian Genome Research Facility (Parkville, Vic, Australia). Hybridisation was performed at low stringency (hybridisation at $50^{\circ} \mathrm{C}$ followed by washing in $2 \times$ SSC at room temperature), medium stringency (hybridisation at $59^{\circ} \mathrm{C}$, washing in $0.1 \times \mathrm{SSC}$ at $59^{\circ} \mathrm{C}$ ), and high stringency (hybridisation at $68^{\circ} \mathrm{C}$, washing in $0.1 \times$ SSC at $68^{\circ} \mathrm{C}$ ), and detected by using chemiluminescence as recommended by the manufacturer. Bacteria were considered probe-positive if the intensity of the spot was similar to that of the positive control.

\section{Bacterial adherence to HEp-2 cells}

The Center for Vaccine Development method was used to determine the pattern of bacterial adherence to HEp-2 epithelial cells [62]. The criteria used to assign bacterial adherence to a particular pattern have been described previously [20].

\section{Type I pili production}

The expression of Type I pili was determined by investigating bacteria for mannose-sensitive haemagglutination of guinea pig erythrocytes. For these assays, bacteria were grown in Brain Heart Infusion broth (Oxoid Ltd., Basingstoke, England) or Antibiotic Medium No. 3 (Penassay broth, PAB; Oxoid Ltd.) at $37^{\circ} \mathrm{C}$ without shaking, and tested for haemagglutination using the method described by Iida et al. [63]. E. coli strains, LF82 and 52D11, were used as positive and negative controls, respectively. Strains that were haemagglutination-negative were retested after passage through Brain Heart Infusion broth to enhance the expression of Type I pili.

\section{Abbreviations used}

A/E: attacing-effacing; aEPEC: atypical EPEC; BFP: bundleforming pili; BHIB: brain heart infusion broth; Cdt: cytolethal distending toxin; EHEC: enterohaemorrhagic Escherichia coli; EPEC: enteropathogenic E. coli; LEE: locus for enterocyte effacement; Lpf: long polar fimbriae; MLST: multi-locus sequence typing; pEAF: EPEC adherence factor plasmid; REPEC: rabbit-specific EPEC; STEC: Shiga toxin-producing E. coli; tEPEC: typical EPEC.

\section{Authors' contributions}

SMT and MT contributed to the design of the study, performed the PCR and assays and contributed to the preparation of the manuscript. $\mathrm{KA}, \mathrm{AB}$ and $\mathrm{VBW}$ performed the hybridisation, haemagglutination and tissue culture assays and contributed to the preparation of the manu- script. WQ and TSW interpreted the raw MSLT data and contributed to the preparation of the manuscript. RMRB conceived and designed the study and oversaw the preparation of the manuscript. All authors read and approved the final manuscript.

\section{Additional material}

\section{Additional file 1}

PCR primers and conditions used in this study, and sizes of PCR amplicons.

Click here for file

[http://www.biomedcentral.com/content/supplementary/14712180-9-117-S1.pdf]

\section{Acknowledgements}

We are grateful to Doctors Jenny Bennett, Karl Bettelheim, Robert Cantey, Arlette Darfeuille-Michaud, Steven Djordjevic, Myron M Levine, Eric Oswald, and Peter Reeves for the gift of bacteria used in this study. This work was supported by grants from the Australian National Health and Medical Research Council and the Australian Research Council.

\section{References}

I. Robins-Browne RM: Traditional enteropathogenic Escherichia coli of infantile diarrhea. Rev Infect Dis 1987, 9:28-53.

2. Trabulsi LR, Keller R, Gomes TAT: Typical and atypical enteropathogenic Escherichia coli. Emerg Infect Dis 2002, 8:508-5I3.

3. Moon HW, Whipp SC, Argenzio RA, Levine MM, Giannella RA: Attaching and effacing activities of rabbit and human enteropathogenic Escherichia coli in pig and rabbit intestines. Infect Immun 1983, 4I: |340-135 I.

4. Rothbaum RJ, Partin JC, Saalfield K, McAdams AJ: An ultrastructural study of enteropathogenic Escherichia coli infection in human infants. Ultrastruct Pathol 1983, 4:291-304.

5. Tzipori S, Robins-Browne RM, Gonis G, Hayes J, Withers M, McCartney E: Enteropathogenic Escherichia coli enteritis: evaluation of gnotobiotic piglets as a model of human infection. Gut 1985, 26:570-578.

6. Celli J, Deng W, Finlay BB: Enteropathogenic Escherichia coli (EPEC) attachment to epithelial cells: exploiting the host cell cytoskeleton from the outside. Cell Microbiol 2000, 2: I-9.

7. Tobe T, Hayashi T, Han CG, Schoolnik GK, Ohtsubo E, Sasakawa C: Complete DNA sequence and structural analysis of the enteropathogenic Escherichia coli adherence factor plasmid. Infect Immun 1999, 67:5455-5462.

8. Cleary J, Lai LC, Shaw RK, Straatman-Iwanowska A, Donnenberg MS, Frankel G, Knutton S: Enteropathogenic Escherichia coli (EPEC) adhesion to intestinal epithelial cells: role of bundle-forming pili (BFP), EspA filaments and intimin. Microbiology 2004, I 50:527-538.

9. Tobe T, Sasakawa C: Role of bundle-forming pilus of enteropathogenic Escherichia coli in host cell adherence and in microcolony development. Cell Microbiol 200I, 3:579-585.

10. Bieber D, Ramer SW, Wu CY, Murray WJ, Tobe T, Fernandez R, Schoolnik GK: Type IV pili, transient bacterial aggregates, and virulence of enteropathogenic Escherichia coli. Science 1998, 280:2||4-2| 18 .

II. Donnenberg MS, Tacket CO, James SP, Losonsky G, Nataro JP, Wasserman SS, Kaper JB, Levine MM: Role of the eaeA gene in experimental enteropathogenic Escherichia coli infection. J Clin Invest 1993, 92:1412-1417.

12. Levine MM, Nataro JP, Karch H, Baldini MM, Kaper JB, Black RE, Clements ML, O'Brien AD: The diarrheal response of humans to some classic serotypes of enteropathogenic Escherichia coli is dependent on a plasmid encoding an enteroadhesiveness factor. J Infect Dis 1985, I 52:550-559. 
13. Kaper JB: Defining EPEC. Rev Microbiol 1996, 27(suppl I):130-133.

14. Nguyen RN, Taylor LS, Tauschek M, Robins-Browne RM: Atypical enteropathogenic Escherichia coli infection and prolonged diarrhea in children. Emerg Infect Dis 2006, 1 2:597-603.

15. Afset JE, Bevanger L, Romundstad P, Bergh K: Association of atypical enteropathogenic Escherichia coli (EPEC) with prolonged diarrhoea. J Med Microbiol 2004, 53: I I37-I I 44.

16. Hill SM, Phillips AD, Walker-Smith JA: Enteropathogenic Escherichia coli and life threatening chronic diarrhoea. Gut 1991, 32:154-158.

17. Bielaszewska M, Middendorf B, Kock R, Friedrich AW, Fruth A, Karch $H$, Schmidt MA, Mellmann A: Shiga toxin-negative attaching and effacing Escherichia coli: distinct clinical associations with bacterial phylogeny and virulence traits and inferred in-host pathogen evolution. Clin Infect Dis 2008, 47:208-217.

18. Hornitzky MA, Mercieca K, Bettelheim KA, Djordjevic SP: Bovine feces from animals with gastrointestinal infections are a source of serologically diverse atypical enteropathogenic Escherichia coli and Shiga toxin-producing $E$. coli strains that commonly possess intimin. Appl Environ Microbiol 2005, 7I:3405-34I2.

19. Pohl PH, Peeters JE, Jacquemin ER, Lintermans PF, Mainil JG: Identification of eae sequences in enteropathogenic Escherichia coli strains from rabbits. Infect Immun 1993, 6 I:2203-2206.

20. Robins-Browne RM, Bordun A-M, Tauschek M, Bennett-Wood V, Russell J, Oppedisano F, Lister NA, Bettelheim KA, Fairley CK, Sinclair MI, et al: Atypical enteropathogenic Escherichia coli: a leading cause of community-acquired gastroenteritis in Melbourne, Australia. Emerg Infect Dis 2004, I 0: 1797-1805.

21. Adams LM, Simmons C, Rezmann L, Strugnell RA, Robins-Browne R Identification and characterization of a K88- and CS3 I A-like operon of a rabbit enteropathogenic Escherichia coli strain which encodes fimbriae involved in the colonization of rabbit intestine. Infect Immun 1997, 65:5222-5230.

22. Keller R, Ordonez JG, de Oliveira RR, Trabulsi LR, Baldwin TJ, Knutton S: Afa, a diffuse adherence fibrillar adhesin associated with enteropathogenic Escherichia coli. Infect Immun 2002, 70:268I-2689.

23. Labigne-Roussel AF, Lark D, Schoolnik G, Falkow S: Cloning and expression of an afimbrial adhesin (AFA-I) responsible for $P$ blood group-independent, mannose-resistant hemagglutination from a pyelonephritic Escherichia coli strain. Infect Immun 1984, 46:25I-259.

24. Wolf MK, Andrews GP, Fritz DL, Sjogren RW Jr, Boedeker EC: Characterization of the plasmid from Escherichia coli RDEC I that mediates expression of adhesin AF/R I and evidence that AF/R I pili promote but are not essential for enteropathogenic disease. Infect Immun 1988, 56: I 846- I857.

25. Nataro JP, Yikang D, Yingkang D, Walker K: AggR, a transcriptional activator of aggregative adherence fimbria I expression in enteroaggregative Escherichia coli. J Bacteriol 1994, I 76:469|-4699.

26. Toma C, Martinez EE, Song T, Miliwebsky E, Chinen I, lyoda S, Iwanaga $M$, Rivas M: Distribution of putative adhesins in different seropathotypes of Shiga toxin-producing Escherichia coli. Clin Microbiol 2004, 42:4937-4946.

27. Smith JL, Bayles DO: The contribution of cytolethal distending toxin to bacterial pathogenesis. Crit Rev Microbiol 2006 , 32:227-248.

28. Scaletsky ICA, Michalski J, Torres AG, Dulguer MV, Kaper JB: Identification and characterization of the locus for diffuse adherence, which encodes a novel afimbrial adhesin found in atypical enteropathogenic Escherichia coli. Infect Immun 2005, 73:4753-4765.

29. Levine MM: Escherichia coli that cause diarrhea: enterotoxigenic, enteropathogenic, enteroinvasive, enterohemorrhagic, and enteroadherent. J Infect Dis 1987, 155:377-389.

30. Nataro JP, Kaper JB: Diarrheagenic Escherichia coli. Clin Microbiol Rev 1998, II:| |42-201.

31. Robins-Browne RM: Escherichia coli strains that cause diarrhoea: models of bacterial pathogenesis. In Recent Advances in Microbiology Volume 2. Edited by: Gilbert GL. Melbourne: Australian Society For Microbiology; 1994:292-375.

32. Afset JE, Anderssen E, Bruant G, Harel J, Wieler L, Bergh K: Phylogenetic backgrounds and virulence profiles of atypical enter- opathogenic Escherichia coli strains from a case-control study using multilocus sequence typing and DNA microarray analysis. J Clin Microbiol 2008, 46:2280-2290.

33. Kukuruzovic R, Robins-Browne RM, Anstey NM, Brewster DR Enteric pathogens, intestinal permeability and nitric oxide production in acute gastroenteritis. Pediatr Infect Dis J 2002, 21:730-739.

34. Feng P, Lampel KA, Karch H, Whittam TS: Genotypic and phenotypic changes in the emergence of Escherichia coli OI57:H7. J Infect Dis 1998, 177:1750-1753.

35. Lacher DW, Steinsland H, Blank TE, Donnenberg MS, Whittam TS: Molecular evolution of typical enteropathogenic Escherichia coli: clonal analysis by multilocus sequence typing and virulence gene allelic profiling. J Bacteriol 2007, 189:342-350.

36. Robins-Browne RM, Tokhi AM, Adams LM, Bennett-Wood V, Moisidis AV, Krejany EO, O'Gorman LE: Adherence characteristics of attaching and effacing strains of Escherichia coli from rabbits. Infect Immun 1994, 62: I 584-I592.

37. Karmali MA, Mascarenhas M, Shen S, Ziebell K, Johnson S, Reid-Smith R, Isaac-Renton J, Clark C, Rahn K, Kaper JB: Association of genomic $O$ island I 22 of Escherichia coli EDL 933 with verocytotoxin-producing Escherichia coli seropathotypes that are linked to epidemic and/or serious disease. J Clin Microbiol 2003, 4I:4930-4940.

38. Afset JE, Bruant G, Brousseau R, Harel J, Anderssen E, Bevanger L, Bergh K: Identification of virulence genes linked with diarrhea due to atypical enteropathogenic Escherichia coli by DNA microarray analysis and PCR. J Clin Microbiol 2006, 44:3703-37II.

39. Khan NA, Kim Y, Shin S, Kim KS: FimH-mediated Escherichia coli $K I$ invasion of human brain microvascular endothelial cells. Cell Microbiol 2007, 9:169-178.

40. Mulvey MA: Adhesion and entry of uropathogenic Escherichia coli. Cell Microbiol 2002, 4:257-27I.

4I. Moreira CG, Carneiro SM, Nataro JP, Trabulsi LR, Elias WP: Role of type I fimbriae in the aggregative adhesion pattern of enteroaggregative Escherichia coli. FEMS Microbiol Lett 2003, 226:79-85

42. Moreira CG, Palmer K, Whiteley M, Sircili MP, Trabulsi LR, Castro $A F$, Sperandio V: Bundle-forming pili and EspA are involved in biofilm formation by enteropathogenic Escherichia coli. J Bacteriol 2006, | 88:3952-396|.

43. Boudeau J, Barnich N, Darfeuille-Michaud A: Type I pili-mediated adherence of Escherichia coli strain LF82 isolated from Crohn's disease is involved in bacterial invasion of intestinal epithelial cells. Mol Microbiol 200I, 39: I272-I 284

44. Francis $C L$, Jerse $A E$, Kaper JB, Falkow S: Characterization on interactions of enteropathogenic Escherichia coli OI27:H6 with mammalian cells in vitro. J Infect Dis 1991, 164:693-703.

45. Orskov $F$ : On the occurrence of $E$. coli belonging to O-group 26 in cases of infantile diarrhoea and white scours. Acta Pathologica et Microbiologica Scandinavica 195I, 29:373-378.

46. Taylor J, Maltby MP, Payne JM: Factors influencing the response of ligated rabbit-gut segments to injected Escherichia coli. Journal of Pathology and Bacteriology 1958, 76:491-499.

47. Taylor J, Wilkins MP, Payne JM: Relation of rabbit gut reactions to enteropathogenic Escherichia coli. Br J Exp Pathol 196I, 42:43-52.

48. Taylor J, Bettelheim KA: The action of chloroform-killed suspensions of enteropathogenic Escherichia coli on ligated rabbit-gut segments. J Gen Microbiol I 966, 42:309-3I3.

49. Robins-Browne RM, Yam WC, O'Gorman LE, Bettelheim KA: Examination of archetypal strains of enteropathogenic Escherichia coli for properties associated with bacterial virulence. I Med Microbiol 1993, 38:222-226.

50. Camguilhem $R$, Milon A: Biotypes and $O$ serogroups of Escherichia coli involved in intestinal infection of weaned rabbits: clues to diagnosis of pathogenic strains. J Clin Microbiol 1989, 27:743-747.

5I. Peeters JE, Geeroms R, Orskov F: Biotype, serotype, and pathogenicity of attaching and effacing enteropathogenic Escherichia coli strains isolated from diarrheic commercial rabbits. Infect Immun 1988, 56: I442-I448.

52. Perna NT, Plunkett G, Burland V, Mau B, Glasner JD, Rose DJ, Mayhew GF, Evans PS, Gregor J, Kirkpatrick HA, et al: Genome 
sequence of enterohaemorrhagic Escherichia coli O157:H7. Nature 200I, 409:529-533.

53. Vial P, Robins-Browne R, Lior H, Prado V, Kaper JB, Nataro JP, Maneval D, Elsayed A, Levine MM: Characterization of enteroadherent-aggregative Escherichia coli, a putative agent of diarrheal disease. J Infect Dis 1988, I 58:70-79.

54. Doughty S, Sloan J, Bennett-Wood V, Robertson M, Robins-Browne RM, Hartland EL: Identification of a novel fimbrial gene cluster related to long polar fimbriae in locus of enterocyte effacement-negative strains of enterohemorrhagic Escherichia coli. Infect Immun 2002, 70:676I-6769.

55. Pillien F, Chalareng C, Boury M, Tasca C, De Rycke J, Milon A: Role of adhesive factor/rabbit 2 in experimental enteropathogenic Escherichia coli 0103 diarrhea of weaned rabbit. Vet Microbiol 1996, 50:105-115.

56. Cantey JR, Blake RK: Diarrhea due to Escherichia coli in the rabbit: a novel mechanism. J Infect Dis 1977, 135:454-462.

57. Hull SI, Hull RA, Minshew BH, Falkow S: Genetics of hemolysin of Escherichia coli. J Bacteriol 1982, I5 I:1006-1012.

58. Ausubel FM, Brent R, Kingston RE, Moore DD, Seidman JG, Smith JA, Struhl K: Current protocols in molecular biology New York, NY: John Wiley \& Sons, Inc; 2003.

59. Kumar S, Tamura K, Jakobsen IB, Nei M: MEGA2: Molecular Evolutionary Genetics Analysis Software. Tempe, Arizona, USA, Arizona State University; 200I.

60. Ramachandran V, Brett K, Hornitzky MA, Dowton M, Bettelheim KA Walker MJ, Djordjevic SP: Distribution of intimin subtypes among Escherichia coli isolates from ruminant and human sources. J Clin Microbiol 2003, 41:5022-5032.

61. Muller D, Hagedorn P, Brast S, Heusipp G, Bielaszewska M, Friedrich AW, Karch H, Schmidt MA: Rapid identification and differentiation of clinical isolates of enteropathogenic Escherichia coli (EPEC), atypical EPEC, and Shiga toxin-producing Escherichia coli by a one-step multiplex PCR method. J Clin Microbiol 2006, 44:2626-2629.

62. Vial PA, Mathewson JJ, Guers L, Levine MM, DuPont HL: Comparison of two assay methods for patterns of adherence to HEp2 cells of Escherichia coli from patients with diarrhea. J Clin Microbiol 1990, 28:882-885.

63. lida K, Mizunoe Y, Wai SN, Yoshida S: Type I fimbriation and its phase switching in diarrheagenic Escherichia coli strains. Clin Diagn Lab Immunol 200I, 8:489-495.
Publish with Biomed Central and every scientist can read your work free of charge

"BioMed Central will be the most significant development for disseminating the results of biomedical research in our lifetime. "

Sir Paul Nurse, Cancer Research UK

Your research papers will be:

- available free of charge to the entire biomedical community

- peer reviewed and published immediately upon acceptance

- cited in PubMed and archived on PubMed Central

- yours - you keep the copyright
BioMedcentral 